\title{
Previously unreported complications associated with integrated cage screws following anterior lumbar interbody fusion: report of $\mathbf{2}$ cases
}

\author{
Neginder Saini, MS, ${ }^{1}$ Mohammad Zaidi, BA, ${ }^{1}$ Maureen T. Barry, MD, ${ }^{2}$ and Robert F. Heary, MD ${ }^{1}$ \\ 'Department of Neurological Surgery, Rutgers New Jersey Medical School, Newark, New Jersey; and 2Department of Radiology, \\ Brody School of Medicine at East Carolina University, Greenville, North Carolina
}

\begin{abstract}
Anterior lumbar interbody fusion (ALIF) is a widely performed surgical treatment for various lumbar spine pathologies. The authors present the first reports of virtually identical cases of complications with integrated screws in stand-alone interbody cages. Two patients presented with the onset of S-1 radiculopathy due to screw misplacements following an ALIF procedure. In both cases, an integrated screw from the cage penetrated the dorsal aspect of the S-1 cortical margin of the vertebra, extended into the neural foramen, and injured the traversing left S-1 nerve roots. Advanced neuroimaging findings indicated nerve root impingement by the protruding screw tip. After substantial delays, radiculopathic symptoms were treated with removal of the offending instrumentation, aggressive posterior decompression of the bony and ligamentous structures, and posterolateral fusion surgery with pedicle screw fixation. Postoperative radiographic findings demonstrated decompression of the symptomatic nerve roots via removal of the extruded screw tips from the neural foramina.
\end{abstract}

https://thejns.org/doi/abs/10.3171/2017.6.SPINE161443

KEY WORDS lumbar spine; stand-alone cage; complication; radiculopathy; posterior decompression; posterior fixation

A NTERIOR lumbar interbody fusion (ALIF) was first described by Capener in 1932 to treat spondylolisthesis and involved implanting bone graft into the intervertebral disc space to stimulate fusion between the vertebrae. ${ }^{2}$ During the 1980 s, advances in spinal fusions led to improvements in the ALIF procedure as well as the development of multiple anatomical approaches. ${ }^{6,17,19} \mathrm{Key}$ advantages of the anterior approach include direct visualization and access to the anterior column for a more complete discectomy, the ability to maintain the structural integrity of the posterior musculature and neural elements, better distraction of the involved vertebrae, and the ability to place a larger implant than in other approaches..$^{13,17,19} \mathrm{In}$ addition, sagittal alignment is more easily improved with the use of large, lordotic-shaped cages placed in the lower lumbar spine. Especially for degenerative pathologies, the ALIF procedure has become a mainstay of spinal surgery; however, controversy exists regarding which surgical approach provides the best outcomes. ${ }^{17-19}$

The stand-alone interbody cage device has been proposed as an alternative to traditional supplemental instru- mentation such as pedicle screws, rods, and plates..$^{13}$ Numerous articles have reported the effectiveness of stand-alone interbody cages with integrated fixation screws. ${ }^{6,13,21} \mathrm{We}$ present the first reports of complications with integrated screw placements in 2 different stand-alone interbody cages implanted in the L5-S1 intervertebral disc spaces during ALIF procedures.

\section{Case Reports}

Case 1

History and Examination

In 2015, a 54-year-old man presented with weakness and numbness of the lower extremities following an ALIF surgery that had been performed in June 2014. He had undergone surgery at an outside institution and initially had relief of his symptoms. One week after surgery, severe pain developed in his left leg, which he described as a burning sensation that radiated to his left calf. He rated the pain as a 6 on the visual analog scale (VAS; range $1-10)$.

ABBREVIATIONS ALIF = anterior lumbar interbody fusion; $C S F=$ cerebrospinal fluid.

SUBMITTED December 20,2016. ACCEPTED June 21, 2017.

INCLUDE WHEN CITING Published online January 5, 2018; DOI: 10.3171/2017.6.SPINE161443. 

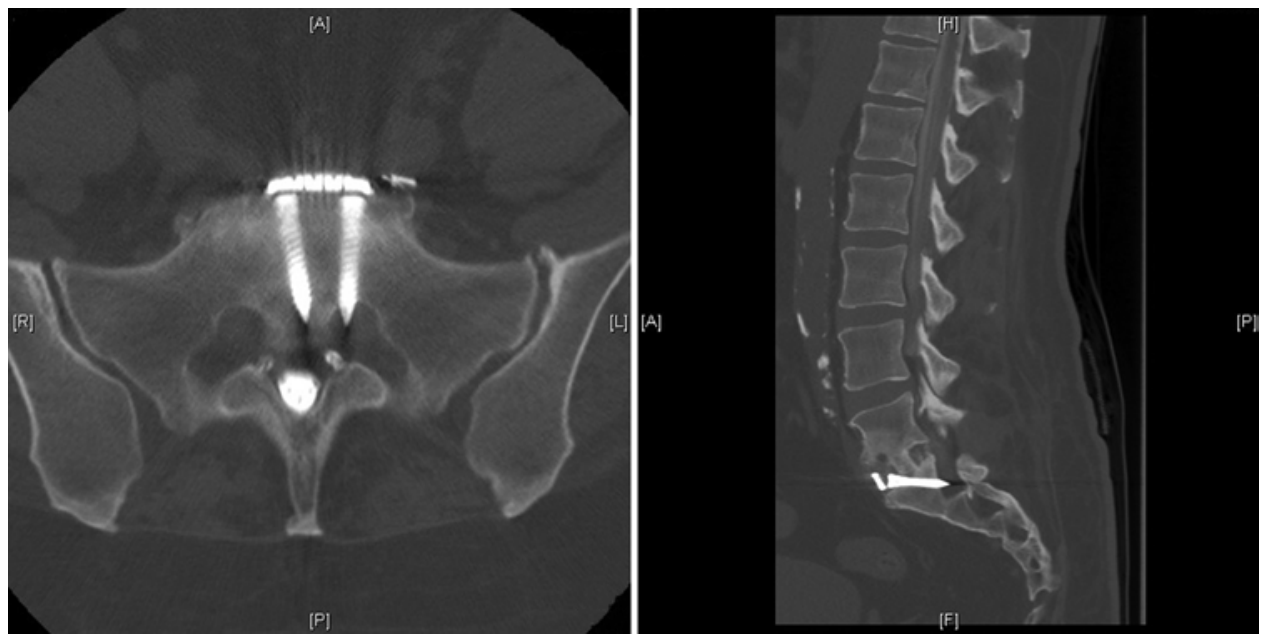

FIG. 1. Case 1. Preoperative axial (left) and sagittal (right) CT myelograms demonstrate the left screw of the interbody cage penetrating into the left S-1 neural foramen. The interbody cage can be seen in the L5-S1 disc space.

His relevant surgical history included a right-sided L5S1 decompression in 1996, a left-sided L5-S1 decompression in 2004, and an ALIF procedure at the L5-S1 level in June 2014. In October 2014, he had undergone a revision left L-5 hemilaminotomy given persistent complaints of left lower-extremity radicular pain. Eight months later, he presented to our institution, stating that the October surgery had not provided relief of his radicular pain.

The initial physical examination revealed dorsiflexion (3/5) and plantarflexion (5-/5) on the left with the remainder of muscle power being normal. Sensation was diminished on the left in the L4-S1 dermatomes. Deep tendon patellar and ankle reflexes were 2+ bilaterally.

As part of the workup for his intractable left lowerextremity pain, a CT myelogram was obtained, revealing an integrated cage in the L5-S1 disc space. The cage was seated deeply in the interspace, and the left S-1 screw tip penetrated the dorsal cortical surface of the S-1 vertebra and projected into the neural foramen and impaled the $S-1$ nerve root (Fig. 1).

\section{Operation}

A posterior approach was used to perform revision surgery at the L5-S1 level. A generous laminectomy at L-5 and laminotomies of the superior aspect of S-1 were performed. The left S-1 nerve root was markedly swollen. With the aid of the operating microscope, this nerve root was gently retracted laterally to allow for exposure of the left S-1 screw tip, which had penetrated into the left S-1 neural foramen and pierced the left S-1 nerve root. The screw tip was drilled down until it was flush with the S-1 vertebral body. There was no evidence of cerebrospinal fluid (CSF) leakage before or after removal of the screw tip, as confirmed by an intraoperative Valsalva maneuver. Lastly, MRI-compatible titanium pedicle screws and plates were placed bilaterally at L-5 and S-1. Autologous bone graft allowed a generous fusion substrate of bone to be packed into the lateral gutters. A standard layered closure was performed.

\section{Postoperative Course}

The patient experienced immediate improvement in the left lower-extremity pain as well as improvement in his strength distally. A postoperative CT scan showed well-positioned pedicle screws and the tip of the left-sided integrated screw no longer in the neural foramen (Fig. 2 ). He was monitored closely for the next year. Routine follow-ups at 6,12 , and 24 weeks revealed significant improvement in left foot strength, mobility, and sensation. He also noted that the pain in his left leg was significantly diminished following the revision surgery. Physical exam revealed persistent dorsiflexion $(4+/ 5)$ and plantarflexion (5-/5) weakness. There was diminished pinprick sensation in the left L4-S1 dermatomes.

At his 1-year follow-up, the numbness, paresthesia, and dysesthetic pain persisted; however, the patient believed that his strength had continued to improve. Over-thecounter antiinflammatory medications adequately controlled his pain. He was able to walk up to half a mile using a cane, which represented a major improvement compared to his preoperative condition. The motor exam was unchanged. There was diminished sensation in the left L-5 and S-1 dermatomal distributions. Plain-film radiographs showed the tip of the left S-1 integrated cage screw to be unchanged compared to its position on postoperative CT.

\section{Case 2}

\section{History and Examination}

In 2014, a 67-year-old woman presented with left leg pain and foot drop following an ALIF and posterior decompression surgery that had been performed in February of that same year. She complained of pain radiating down her left leg as well as numbness, paresthesia, and weakness in the left lower extremity. She stated that after the ALIF surgery, she awoke with left foot drop and persistent pain. Physical therapy had provided minimal benefit and she walked with a cane.

Her spine surgical history included an anterior-posteri- 

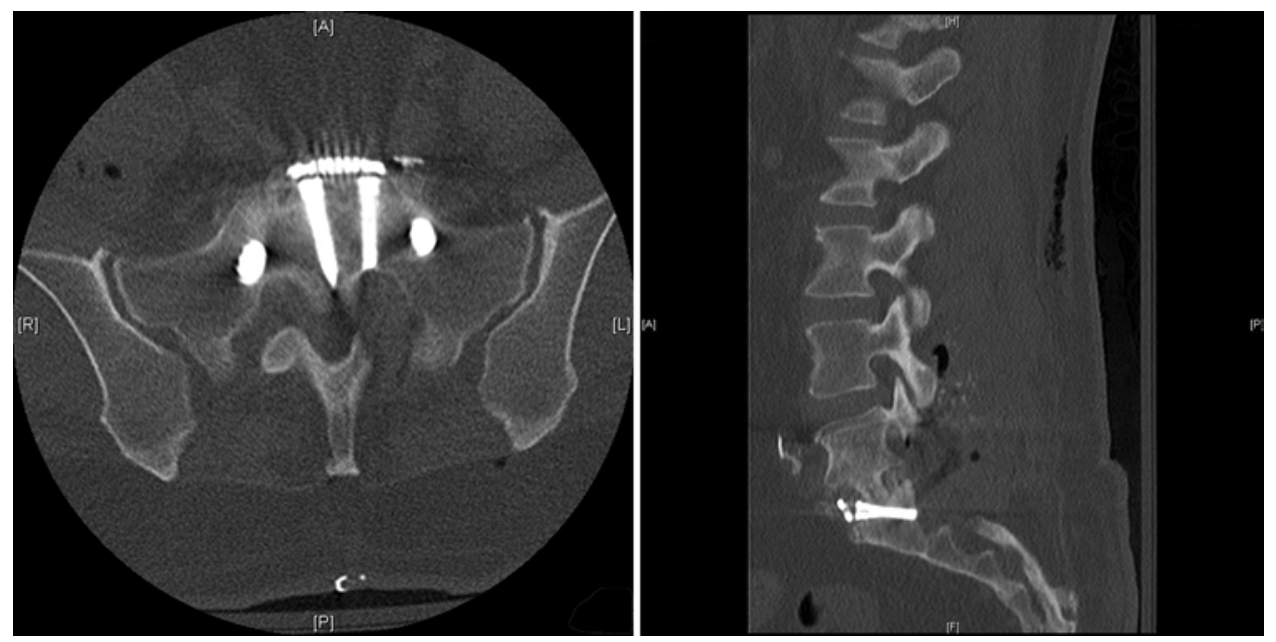

FIG. 2. Case 1. Postoperative axial (left) and sagittal (right) CT studies demonstrate that the left S-1 cage screw has been drilled flush with the vertebral body and no longer extends into the left S-1 neural foramen. Both images show significant bony decompression, which had been performed prior to drilling down the screw tip.

or surgery in 2014 with anterior discectomy and interbody fusion at L5-S1, posterior decompression at L4-5, and bilateral foraminotomies from L-4 to S-1.

Her initial physical examination revealed normal lower-extremity muscle tone. Strength was normal in the right lower extremity with weakness in the left iliopsoas, quadriceps, and hamstrings muscles $(4+/ 5)$, left ankle plantarflexion (4/5), and left ankle dorsiflexion (2/5). She had diminished pinprick sensation in the left L-5 and S-1 dermatomes. Deep tendon patellar reflexes were 3+ bilaterally, and ankle jerk reflexes were absent bilaterally. Straight-leg raise test was positive on the left side with pain radiating to the left toes.

Preoperative MRI studies of the lumbar spine had revealed diminished disc space height at the L5-S1 level and degenerative disc changes at both the L4-5 and L5-S1 levels. After the surgery, because of the left lower-extremity pain and weakness, MRI and plain-film radiography of the lumbar spine were performed, demonstrating the ALIF cage at L5-S1. An artifact on the MRI study precluded accurate assessment of the metallic instrumentation.

The patient had complained bitterly to her operating surgeon of the severe left lower-extremity pain and weakness. Fifteen months after the surgery, without satisfactory resolution of her symptoms, she came to our institution for a second opinion. Given her persistent complaints, a CT myelogram was obtained, revealing posterior decompression at the L4-5 level. There was a left-sided screw tip from the integrated cage at the L5-S1 disc space that directly impinged on the left S-1 nerve root (Fig. 3).

\section{Operation}

A midline incision through the previous scar was used. Left-sided laminectomy was performed from L-4 to S-1 with aggressive bony removal of the left L5-S1 facet joint. With the aid of the operating microscope, the left
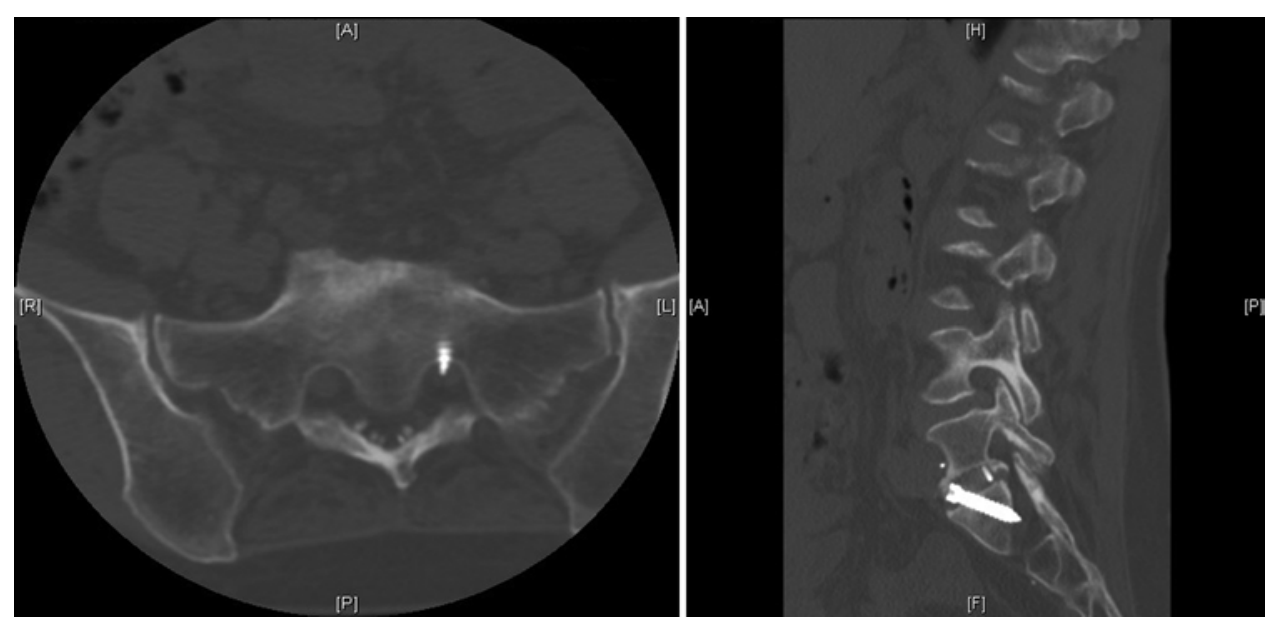

FIG. 3. Case 2. Preoperative axial (left) and sagittal (right) CT myelograms demonstrate penetration of the tip of the left interbody cage screw into the left S-1 neural foramen. 


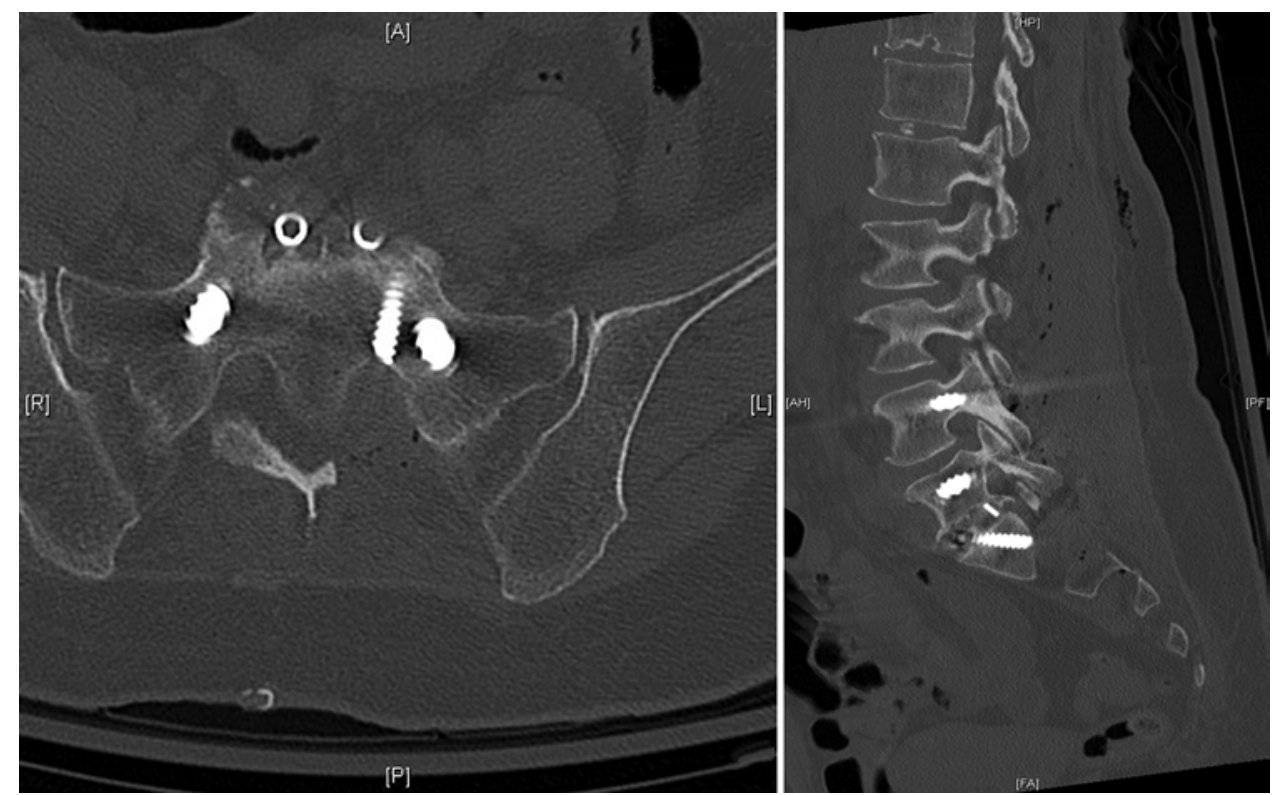

FIG. 4. Case 2. Postoperative axial (left) and sagittal (right) CT scans demonstrate that the left interbody screw has been drilled flush to the vertebral body and no longer extends into the left L-1 neural foramen. Both images show significant bony decompression, which had been performed prior to drilling down the screw tip.

S-1 nerve root was gently retracted laterally to expose the underlying S-1 screw tip from the integrated cage that had penetrated into the S-1 neural foramen. The screw tip was drilled down until flush with the bone. Pedicle screws and plates were placed bilaterally from L-4 to S-1 for stabilization, and autologous iliac crest bone was packed into the lateral gutters for bilateral fusion. Once again, a Valsalva maneuver was performed before and after removal of the screw tip, and no CSF leakage was observed.

\section{Postoperative Course}

Immediately after surgery, a CT scan was obtained, demonstrating good position of the bilateral pedicle screws with the left screw tip from the integrated cage resected flush to the left S-1 vertebra (Fig. 4). The patient's preoperative pain and weakness persisted in the immediate postoperative period.

Over the next year, with evaluations every 3 months, the patient's left leg pain persisted. The prior back pain completely resolved, and she had no right lower-extremity symptoms. Numbness, paresthesia, and weakness also remained. She had been prescribed physical therapy and walked with a cane. Dysesthetic pain in the left leg was present in the S-1 dermatome. She was treated with implantation of a dorsal spinal cord stimulator 1 year after surgery with satisfactory left leg pain control. Radiographs of the lumbar spine showed excellent alignment of the L4-S1 construct with a solid bony arthrodesis.

\section{Discussion}

Multiple studies have compared the stand-alone interbody cage with integrated screws to traditional supplemental fixation methods and concluded that this type of interbody cage provided stability equivalent to supplemen- tal bilateral pedicle screws and anterior plate fixation. ${ }^{13,21}$ Supplemental fixation techniques during ALIF require a secondary posterior surgery, which results in a more extensive, more time-consuming surgery, and increased morbidity and complications; therefore, stand-alone cages with integrated screws were developed to provide sufficient stability of the construct and to reduce approachrelated morbidity. ${ }^{13}$

Inoue et al. and $\mathrm{Li}$ et al. documented nerve root injury caused by outwardly inserted S-1 pedicle screws, which represent the cortical screw trajectory. ${ }^{12,15}$ We present what are to our knowledge the first reports of nerve root injuries caused by misplaced integrated cage screws. In both of the presented cases, prolonged morbidity related to the impaled S-1 nerve roots existed and conservative pain management was ineffective. The surgeons who performed the index procedures with the integrated cage systems - both at outside institutions - were reluctant to obtain advanced imaging studies. In each case, nearly a year had passed with appreciable S-1 radiculopathy complaints before the patients sought a second opinion for management of their debilitating painful conditions. In both cases, CT myelography clearly demonstrated that the screws from the cage violated the posterior S-1 cortical margins and directly impinged on the S-1 nerve roots. Radiographic findings were independently confirmed by a neuroradiologist. In case 1 , there had been a loss of the anatomical midline orientation during placement of the integrated screws, which led to an excessively lateral placement of the left-sided screw. In case 2 , the integrated screw had been placed in the lateral screw hole instead of the midline screw hole. Furthermore, the interbody cages were also seated deeply in the intervertebral disc space, which contributed to the iatrogenic complications in both cases. A revision surgery via a posterior approach was recommended. This approach 
was favored to allow for significant bony decompression of the neural elements to improve the radiculopathy. This approach would also allow for a dural repair, if necessary, since CSF leakage was a concern upon mobilization of the S-1 nerve root and removal of the screw tip. In both cases, despite the screw tips appearing to enter the corresponding S-1 nerve roots, dural violations were not observed through the operating microscope when a Valsalva maneuver was performed.

Specific measures can be attempted to avoid this complication. The loss of midline orientation during surgery can be avoided by obtaining intraoperative anteroposterior fluoroscopic images and ensuring that the pedicles are symmetric. The vertebral bodies are marked 1 level superior and inferior to the disc space by using a marking pen. ${ }^{10}$ Fluoroscopy should also be used in the horizontal and vertical planes after integrated cage placement to ensure midline placement. ${ }^{16}$ The anteroposterior image should demonstrate sacroiliac joints equidistant from spinous processes, spinous processes midline relative to the vertebral column, and transverse processes of equal length. ${ }^{1}$ Furthermore, the implant screw length can be determined by careful review of the preoperative CT scan. Care should be taken to avoid seating the cage too deeply, and a ball-tipped feeler should be used to confirm the depth of the proposed pilot hole before the screw is placed into the vertebra. In addition to bony decompression, a posterolateral fusion with transpedicular screw instrumentation was favored to further stabilize the segment. The rationale for a posterior fusion was 2-fold: the S-1 nerve root would be appreciably swollen (which was observed in both cases) with resulting CSF leakage (which was not observed), and the removal of bone could induce an iatrogenic instability. Incorporating pedicle screw fusion surgeries allowed for stable bony arthrodesis in each of the featured cases. There is still controversy in the literature regarding the indications for instrumentation during ALIF since it has a higher long-term fusion rate than with bone graft only-but also a higher complication profile. ${ }^{3,17,20,21}$ Despite this, multiple studies have indicated that ALIF or posterior lumbar interbody fusion with supplemental posterior instrumentation improves long-term fusion rates and stability. ${ }^{3,6,9,13,17,21}$ In both cases described, through a posterior approach, the S-1 nerve root was retracted laterally and the involved screw material was removed from the neural foramen following bony decompression. In case 2 , persistent, severe pain required an additional surgery for adequate pain control. In both cases, radiographs indicated proper alignment and solid fusions. Both pre- and postoperative CT scans were obtained to document a successful revision surgery.

In cases in which radicular complaints persist in the postoperative period, advanced neuroimaging is essential to confirm successful decompression of the involved nerve roots. Static plain radiographs provide excellent bone detail and are relatively low cost; however, they fail to provide significant information about the neural elements. Computed tomography is a superior tool for assessing the success of the bony aspects of spinal fusion procedures, and studies show a higher detection of abnormalities compared with plain radiography. ${ }^{4}$ When combined with my- elography, CT is considered to be the gold standard to rule out any nerve compression. ${ }^{5,8,10,14}$ Initial pain from surgery is expected for the first few postoperative weeks, but after 6 weeks, ongoing complaints of pain and late worsening symptoms would probably be best addressed with advanced neuroimaging to rule out iatrogenic concerns. Bone windows are also recommended to aid in the CT interpretation. ${ }^{7,11}$ Many spine surgeons believe conventional radiographs are sufficient and express concerns about radiation exposure; however, we present evidence that advanced radiological imaging is a necessary adjunct to plain-film radiography and clinical assessments for improved outcomes in cases with persistent radicular pain.

\section{Conclusions}

Surgeons should recognize the nerve injury risk during spinal fusions with integrated screws using a standalone interbody cage. Proper patient positioning, maintenance of midline orientation and depth, and intraoperative horizontal and vertical fluoroscopic imaging can help to minimize the chances of this complication. If persistent radicular complaints are present, advanced radiological imaging is advised in the postoperative period to ensure proper anatomical visualization of the implants. Posterior revision approaches were successful in decompressing the S-1 nerve roots and allowing for solid fusions.

\section{References}

1. Bontrager KL, Lampignano JP: Bontrager's Handbook of Radiographic Positioning and Techniques, ed 7. St. Louis: Mosby/Elsevier, 2010

2. Capener N: Spondylolisthesis. Br J Surg 19:374-386, 1932

3. Choi KC, Ryu KS, Lee SH, Kim YH, Lee SJ, Park CK: Biomechanical comparison of anterior lumbar interbody fusion: stand-alone interbody cage versus interbody cage with pedicle screw fixation - a finite element analysis. BMC Musculoskelet Disord 14:220, 2013

4. Choudhri TF, Mummaneni PV, Dhall SS, Eck JC, Groff MW, Ghogawala Z, et al: Guideline update for the performance of fusion procedures for degenerative disease of the lumbar spine. Part 4: radiographic assessment of fusion status. J Neurosurg Spine 21:23-30, 2014

5. Chow SP, Leong JC, Ma A, Yau AC: Anterior spinal fusion or deranged lumbar intervertebral disc. Spine (Phila Pa 1976) 5:452-458, 1980

6. Cole CD, McCall TD, Schmidt MH, Dailey AT: Comparison of low back fusion techniques: transforaminal lumbar interbody fusion (TLIF) or posterior lumbar interbody fusion (PLIF) approaches. Curr Rev Musculoskelet Med 2:118126, 2009

7. Costelloe CM, Chuang HH, Chasen BA, Pan T, Fox PS, Bassett RL, et al: Bone windows for distinguishing malignant from benign primary bone tumors on FDG PET/CT. J Cancer $4: 524-530,2013$

8. Harmon PH: A simplified surgical technic for anterior lumbar diskectomy and fusion; avoidance of complications; anatomy of the retroperitoneal veins. Clin Orthop Relat Res 37:130-144, 1964

9. Heary RF, Bono CM: Circumferential fusion for spondylolisthesis in the lumbar spine. Neurosurg Focus 13(1):E3, 2002

10. Heary RF, Yanni DS, Halim AY, Benzel EC: Anterior lumbar interbody fusion, in Steinmetz MP, Benzel EC (eds): Benzel's Spine Surgery, ed 4. Philadelphia: Elsevier, 2017, pp 655-666 
11. Hida K, Iwasaki Y, Koyanagi I, Abe H: Bone window computed tomography for detection of dural defect associated with cervical ossified posterior longitudinal ligament. Neurol Med Chir (Tokyo) 37:173-176, 1997

12. Inoue $M$, Inoue $\mathrm{G}$, Ozawa $\mathrm{T}$, Miyagi M, Kamoda $\mathrm{H}$, Ishikawa $\mathrm{T}$, et al: L5 spinal nerve injury caused by misplacement of outwardly-inserted S1 pedicle screws. Eur Spine J 22 (Suppl 3):S461-S465, 2013

13. Kornblum MB, Turner AW, Cornwall GB, Zatushevsky MA, Phillips FM: Biomechanical evaluation of stand-alone lumbar polyether-ether-ketone interbody cage with integrated screws. Spine J 13:77-84, 2013

14. Kozak JA, O'Brien JP: Simultaneous combined anterior and posterior fusion. An independent analysis of a treatment for the disabled low-back pain patient. Spine (Phila Pa 1976) 15:322-328, 1990

15. Li G, Lv G, Passias P, Kozanek M, Metkar US, Liu Z, et al: Complications associated with thoracic pedicle screws in spinal deformity. Eur Spine J 19:1576-1584, 2010

16. Malhotra A, Kalra VB, Wu X, Grant R, Bronen RA, Abbed KM: Imaging of lumbar spinal surgery complications. Insights Imaging 6:579-590, 2015

17. Mobbs RJ, Loganathan A, Yeung V, Rao PJ: Indications for anterior lumbar interbody fusion. Orthop Surg 5:153-163, 2013

18. Mobbs RJ, Phan K, Daly D, Rao PJ, Lennox A: Approach-related complications of anterior lumbar interbody fusion: results of a combined spine and vascular surgical team. Global Spine J 6:147-154, 2016

19. Mobbs RJ, Phan K, Malham G, Seex K, Rao PJ: Lumbar interbody fusion: techniques, indications and comparison of interbody fusion options including PLIF, TLIF, MI-TLIF, OLIF/ATP, LLIF and ALIF. J Spine Surg 1:2-18, 2015

20. Mummaneni PV, Dhall SS, Eck JC, Groff MW, Ghogawala $\mathrm{Z}$, Watters WC III, et al: Guideline update for the performance of fusion procedures for degenerative disease of the lumbar spine. Part 11: interbody techniques for lumbar fusion. J Neurosurg Spine 21:67-74, 2014

21. von Keudell A, Alimi M, Gebhard H, Härtl R: Adult degenerative scoliosis with spinal stenosis treated with stand-alone cage via an extreme lateral transpsoas approach; a case report and literature review. Arch Bone Jt Surg 3:124-129, 2015

\section{Disclosures}

The authors declare no financial or material support from grants or organizations.

\section{Author Contributions}

Conception and design: Heary. Acquisition of data: Heary, Saini, Zaidi. Analysis and interpretation of data: all authors. Drafting the article: Heary, Saini, Zaidi. Critically revising the article: all authors. Reviewed submitted version of manuscript: all authors. Approved the final version of the manuscript on behalf of all authors: Heary. Study supervision: Heary.

\section{Correspondence}

Robert F. Heary: Rutgers New Jersey Medical School, Newark, NJ.heary@njms.rutgers.edu. 